\title{
Dynamic Adsorption of Chromium Ions onto Natural and Crosslinked Chitosan Membranes for Wastewater Treatment
}

\author{
Emerson Meneghetti, Paula Baroni, Rodrigo Silveira Vieira, \\ Meuris Gurgel Carlos da Silva, Marisa Masumi Beppu* \\ School of Chemical Engineering, State University of Campinas, UNICAMP \\ P.O. Box 6066, 13081-970 Campinas - SP, Brazil
}

Received: October 19, 2009; Revised: December 20, 2009

\begin{abstract}
Water pollution with heavy metals is a matter of major concern for public health and also for natural resource management. The present study investigated the effect of chemical modifications on biopolymeric adsorbents (based on chitosan membranes) for chromium removal using fixed-bed dynamic adsorption technique. Parameters such as flow rate, initial concentration and crosslinking agents were evaluated, from a practical point-of-view, in order to optimize the adsorption capacity of natural, glutaraldehyde and epichlorohydrin crosslinked chitosan membranes. The adsorption capacity of natural and epiclorohydrin-crosslinked chitosan membranes were very close to each other; however, glutaraldehyde-crosslinked chitosan membranes presented nearly twice the adsorption capacity compared to the other membranes, being the most promising adsorbent in such mass-transfer systems.
\end{abstract}

Keywords: chitosan, heavy metal, chromium, adsorption

\section{Introduction}

The contamination of environment due to heavy metals, even at low concentration, is becoming a serious problem and health concern due to the typical high toxicity and unbiodegrability of such contaminants ${ }^{1}$. Among these metals, chromium ions, which are highly toxic, are extensively used in a large variety of industrial activities.

Chromium is only stable in the environment when in its trivalent and the hexavalent forms. $\mathrm{Cr}$ (VI) is highly toxic and carcinogenic while $\mathrm{Cr}$ (III) presents less toxicity and can be considered an essential micronutrient ${ }^{2}$. However, in significant concentrations, $\mathrm{Cr}$ (III) can cause further adverse effects because of its increased ability to coordinate various organic compounds resulting in inhibition of some metallo-enzyme systems ${ }^{3}$.

The removal of heavy metals from industrial wastewater can be achieved using adsorption in a fixed bed column ${ }^{4}$, where the performance can be evaluated through use of the well-known breakthrough curves. This configuration the most interesting from a practical point of view since it allows the treatment of a higher amount of wastewater in a continuous flow process.

The adsorption capacity of several low-cost adsorbents has been investigated, mainly using biopolymers, such as chitosan, which are obtained from renewable sources and also adsorb metallic ions selectively ${ }^{5-8}$. Its chelating properties are attributed to the amino and hydroxyl groups present in chitosan chain, which act as chelation sites for several metals ${ }^{9-10}$.

Crosslinking reactions with chitosan are performed by using specific bifunctional chemicals that react with determined groups of the biopolymer. The purposed of this kind of chemical modification is to avoid chitosan dissolution in acidic solutions, thus improving the biopolymer mechanical resistance and enhancing its adsorption capacity. Glutaraldehyde and epichlorohydrin are two important chemicals used with this intention. The former reacts preferably with amino groups while the latter reacts with hydroxyl groups.

In a previous study ${ }^{11}$ we investigated the effect of crosslinking reaction in the chromium adsorption properties on chitosan mem- branes in batch adsorption experiments. In this study, we focused in investigating the dynamic adsorption properties using fixed-bed experiments, which are more applicable to real industrial processes. Statistical analyses were also performed in order to evaluate the effects of input parameters (initial concentration of chromium, flow rate and crosslinking agent) on the adsorption capacity of chitosan membranes.

\section{Materials and Methods}

\subsection{Adsorbent preparation}

Chitosan solution $2.5 \%\left(\mathrm{w}_{\mathrm{w}} \mathrm{w}^{-1}\right)$ was prepared dissolving chitosan flakes (purchased from Sigma-USA, commercial grade) in acetic acid $0.50 \mathrm{~mol} . \mathrm{L}^{-1}$ solution (analytical grade, purchased from Labsynth-Brazil-99.7\% pure). The solutions were filtered through $28 \mu \mathrm{m}$ porosity filter and stored at $4{ }^{\circ} \mathrm{C}$. The preparation of porous chitosan membranes followed the procedure described by Beppu and Santana ${ }^{12}$. The solution was spread on a Petri dish, which was kept at $60{ }^{\circ} \mathrm{C}$ until reaching a reduction of $50 \%$ of its initial weight. The membranes were immersed in a solution of $\mathrm{NaOH}\left(1.0 \mathrm{~mol} . \mathrm{L}^{-1}\right)$ for 24 hours to neutralize amino groups and finally they were washed exhaustively with distilled water until all alkali was removed (controlled by measuring the $\mathrm{pH}$ of the rinsing water, that should be neutral) and stored in Milli-Q water.

\subsection{Chemical modifications of membranes}

- Crosslinking with epichlorohydrin $-3.0 \mathrm{~g}$ of natural chitosan membranes were immersed in $50 \mathrm{~mL}$ of $0.01 \mathrm{~mol} . \mathrm{L}^{-1}$ of epichlorohydrin solution, prepared in a 0.067 mol. $\mathrm{L}^{-1} \mathrm{NaOH}$ solution and were kept at $40^{\circ} \mathrm{C}$ under continuous agitation for 2 hours. The membranes were then washed and stored in Milli-Q water at $4{ }^{\circ} \mathrm{C}^{13}$. The molar ratio of epichlorohydrin/ $\mathrm{NH}_{2}$ was 0.02 .

- Crosslinking with glutaraldehyde $-3.0 \mathrm{~g}$ of natural chitosan 
Table 1. Properties of natural and crosslinked chitosan membranes ${ }^{15}$

\begin{tabular}{lccccc}
\hline & Aspect & Deacetilation degree $(\%)$ & Width $(\mathrm{mm})$ & Water content $(\%)$ & Porosity $(\%)$ \\
\hline Natural Chitosan & Opaque & 81.0 & $1.83 \pm 0.07$ & 93.9 & 74.7 \\
GLA-Chitosan & Opaque & - & $1.93 \pm 0.12$ & 91.5 & 43.9 \\
ECH-Chitosan & Opaque & 68.7 & $1.94 \pm 0.05$ & 93.1 & 50.7 \\
\hline
\end{tabular}

Table 2. Experimental conditions for each factor

\begin{tabular}{ccc}
\hline Levels & Initial concentration $\left(\mathrm{mg} . \mathrm{L}^{-1}\right)$ & Flow rate $(\mathrm{mL} / \mathrm{min})$ \\
\hline+ & 250 & 5.5 \\
Central Point & 150 & 4.1 \\
- & 50 & 2.7 \\
\hline
\end{tabular}

membranes were immersed in $50 \mathrm{~mL}$ of $0.75 \%$ w.w ${ }^{-1}$ glutaraldehyde solution and were kept under continuous agitation for 2 hours. The membranes were washed and stored in Milli$\mathrm{Q}$ water at $4{ }^{\circ} \mathrm{C}^{[14]}$. The molar ratio glularaldehyde/ $\mathrm{NH}_{2}$ was 5.0.

The ratio of crosslinking agent and amino groups can have influence in the chromium adsorption properties, but it was not quantitively investigated in this study. The different molar ratio values of glutaraldehyde/amino groups and epichlorohydrin/amino groups were chosen based in the literature ${ }^{13-14}$ as indicated to maximize the $\mathrm{Cr}(\mathrm{VI})$ adsorption capacity.

The deacetilation degree of chitosan was measured by potentiometric titration; the thickness of membranes were measure by a Mitutoyo micrometer; water content was obtained by mass balance after drying the adsorbent within an oven until constant mass was reached; and porosity was measured by using a gravimetric method as explained in other previous studies from the group ${ }^{15}$. Table 1 depicts these properties ${ }^{15}$ for natural and glutaraldehyde and epichlorohydrincrosslinked chitosan. The water content is particularly important to calculate the chromium adsorption in dry base of biopolymer.

\subsection{Adsorption experiments}

Chromium solutions were prepared using potassium dichromate (analytical grade, $\mathrm{K}_{2} \mathrm{Cr}_{2} \mathrm{O}_{7}$ - Sigma-USA-99,9\%), at 50, 150 and $250 \mathrm{mg} . \mathrm{L}^{-1}$. These concentrations were chosen based in a previous study ${ }^{11}$, which determined the maximum adsorbed amounts by static experiments.

To perform the dynamic tests, a plastic column (height $=20 \mathrm{~cm}$, diameter $=1.4 \mathrm{~cm}$ ) was packed with chitosan membrane pieces of $1 \mathrm{~cm}^{2}$. This adsorbent geometry was performed in order to allow comparisons with previous static experiment results ${ }^{11}$. Solution was pumped by using a Masterflex peristaltic pump, taking care to not form air bubbles in the system, which could induce preferential flow paths through the bed. The system was first stabilized using a continuous flow of Milli-Q water for 24 hours. The chromium solution was pumped upward, at $\mathrm{pH}=6.0$, and samples were collected within specified time intervals and the values for total chromium concentration were determined. Total chromium concentration was determined by atomic absorption spectrometry (Perkin Elmer Analyst $100)$ in air-acetylene flame, based on the radiation of chromium atoms at $357.9 \mathrm{~nm}$ ).

The effect of $\mathrm{pH}$ on chromium adsorption using chitosan by static experiments was analyzed and the maximum adsorbed amount occurred at $\mathrm{pH}=6.0$, compared with $\mathrm{pH}=2.0$, on epichlorohydrincrosslinked chitosan ${ }^{11}$. Therefore, in this study the $\mathrm{pH}=6.0$, due the highest adsorption capacity, was used to evaluate the affinity and behavior of chromium ions in dynamic process.
The adsorbed amount of chromium ions $Q$ (mg metal.g ${ }^{-1}$ adsorbent) is obtained through an integral mass balance, as given by Equation 1.

$$
Q=\frac{C_{i}\left(V_{F}-V_{M}\right)-\int_{V_{M}}^{V_{F}} C d V}{W}
$$

in which the integral represents the area below the adsorption curve, obtained through numerical integration using ORIGIN software $V F$, (L) corresponds to the feed volume, where $C(t)$, time concentration (mg. $\left.\mathrm{L}^{-1}\right), C i$ the initial concentration $\left(\mathrm{mg} . \mathrm{L}^{-1}\right)$ in the effluent solution, $V M(\mathrm{~L})$ is the dead volume of the system and $W$ is the weight wet or dry adsorbent $(\mathrm{g})$.

The dimensionless concentration $\left(\mathrm{C}^{*}\right)$ was plotted against the dimensionless time parameter $(\tau)$, in order to compare the different concentrations and adsorbents used, and were calculated according to the following Equations 2 and 3:

$$
\begin{aligned}
& C^{*}=\frac{C(t)}{C_{i}} \\
& \tau=\frac{\varepsilon_{c o l} v_{\text {sup }} t}{L}
\end{aligned}
$$

where $L(\mathrm{~cm})$ and $\varepsilon c o l$ is the length and porosity of the column, respectively, vsup $(\mathrm{cm} / \mathrm{min})$ the superficial velocity in the entrance of bed, $\mathrm{t}$ is the run time and $\tau$ is the dimensionless time parameter, which corresponds physically to the number of displacements, the ratio between the total volume of fluid feed and void volume in the column. The porosity of the column was determined by gravimetric method, by knowing the density of adsorbent and the adsorbent and column geometry. The superficial velocity is calculated dividing the volumetric flow rate by the cross-sectional flow area.

\subsection{Factorial plan}

A factorial plan of $3 \times 2 \times 2$ was used in the present study, in order to study the influence of the following parameters: initial concentration of chromium ions, flow rate and crosslinking agent (varying in three levels - natural chitosan, chitosan crosslinked with epichlorhydrin or glutaraldehyde) on adsorption capacity. Triplicates of the central point between the maximum and minimum flow rate and concentrations were performed, in order to determine the error and the reproducibility level of experiments, assuming the homoscedasticity of the system ${ }^{16}$. Table 2 shows the experimental conditions for each experiment, based on the experimental design. This Table shows the highest and lowest values for each parameter and the central point. The level of flow rates were chosen based in previous studies, obtained using static adsorption experiments, which showed that the adsorption kinetics of chromium ions on chitosan membranes are very slow. A total of 15 experimental tests were performed, including the central point triplicates, which were performed using natural chitosan.

\section{Results and Discussions}

In all experiments, the $\mathrm{pH}$ was kept constant and was equal to 6.0 (adjusted, using $\mathrm{NaOH}$ solution $\left(0.1 \mathrm{~mol} . \mathrm{L}^{-1}\right)$. In this $\mathrm{pH}$ range, it is not probable that the reduction of chromate ions can take place. 


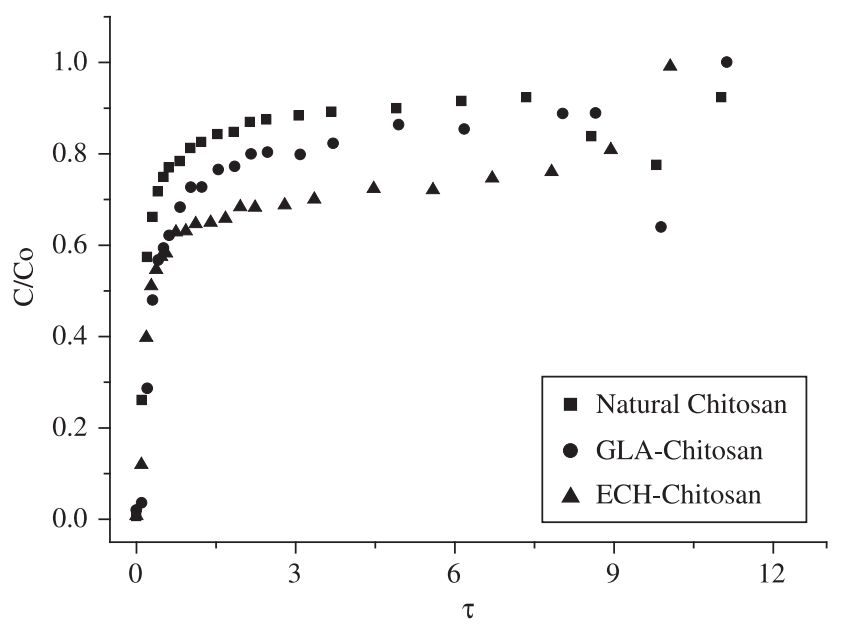

(a)

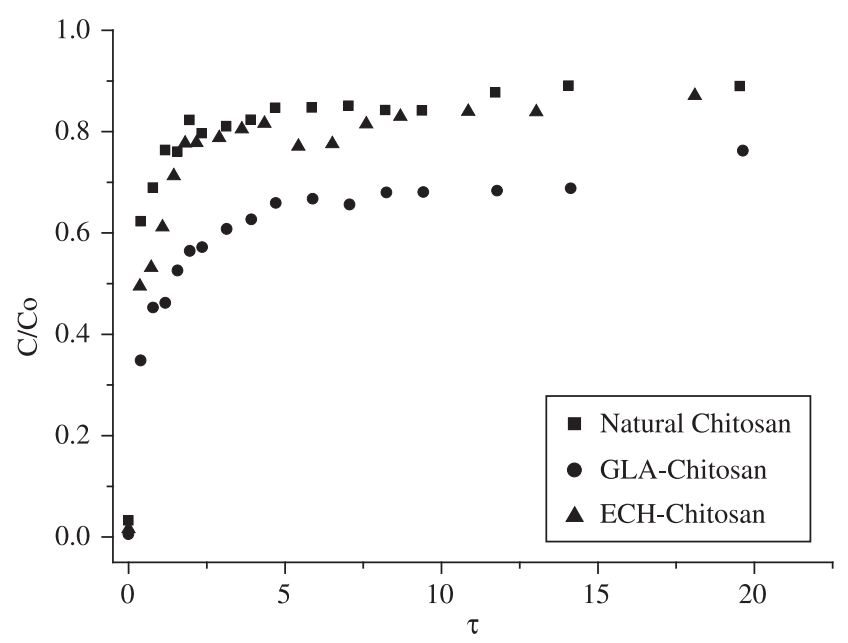

(c)

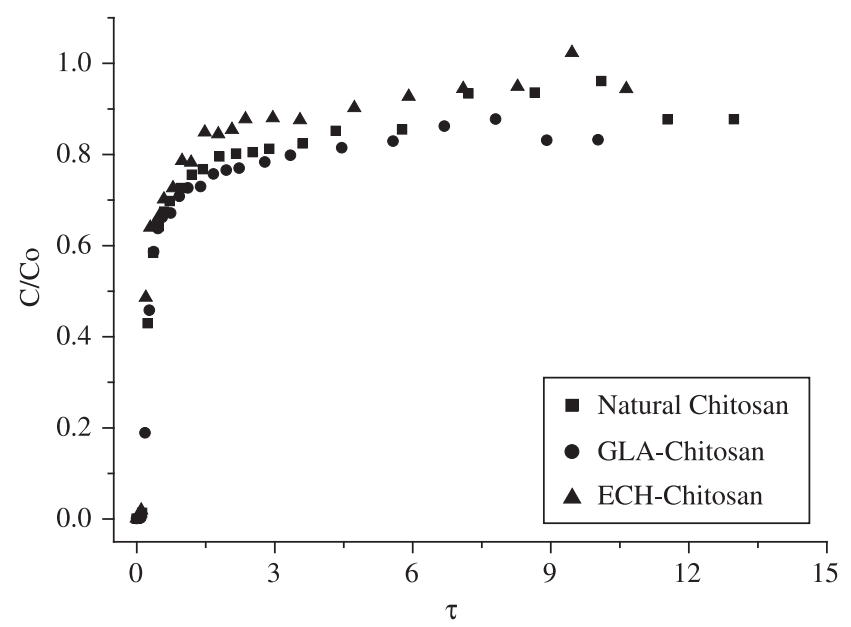

(b)

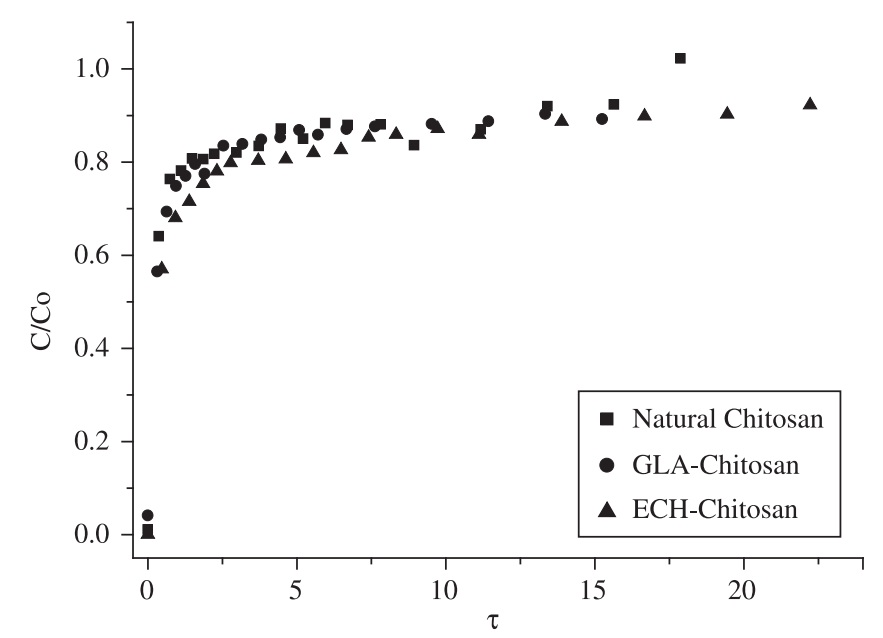

(d)

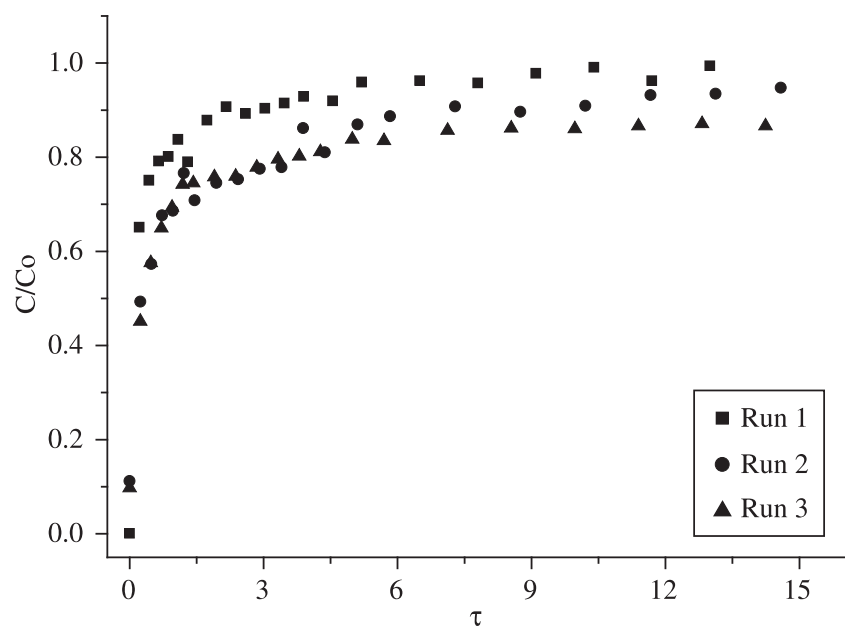

(e)

Figure 1. a, b, c and d - Breakthrough curve triplicates for chromium ions at initial concentrations of 50 and $250 \mathrm{mg} . \mathrm{L}^{-1}$ at flow rates of $2.7 \mathrm{~mL} / \mathrm{min}(\mathrm{a}$ and b) and $5.5 \mathrm{~mL} / \mathrm{min}$ (c and d), respectively. (e) - Breakthrough curve in the central point, on natural chitosan, at flow rate of $4.1 \mathrm{~mL} / \mathrm{min}$ and initial concentration of $150 \mathrm{mg} . \mathrm{L}^{-1}$. 
Dambies et al. ${ }^{17}$ reported that the entire $\mathrm{Cr}$ bound to glutaraldehyde crosslinked chitosan beads at $\mathrm{pH} 4$ was non-enzymatically reduced to $\mathrm{Cr}$ (III) while only $60 \%$ of the $\mathrm{Cr}$ bound to native chitosan beads was in the trivalent form. Boddu et al. ${ }^{18}$ also reported that about $67 \%$ of the $\mathrm{Cr}$ bound to a composite chitosan biosorbent, prepared by coating the ceramic substrate with chitosan gel, was reduced to $\mathrm{Cr}$ (III) at $\mathrm{pH} 4$. All the other experimental conditions were maintained as constant as possible during the tests (equipments, incident light and methods for preparing solution). The breakthrough curves are shown in Figures 1 (a) to (e) on chitosan membranes. The Figures 1 (a), (b), (c) and (d) depict the breakthrough curves for chromium ions at initial concentrations of 50 and $250 \mathrm{mg} . \mathrm{L}^{-1}$ and at flow rates of $2.7 \mathrm{~mL} / \mathrm{min}$ ( $\mathrm{a}$ and $\mathrm{b}$ ) and $5.5 \mathrm{~mL} / \mathrm{min}$ (c and d), respectively. The Figure 1 (e) shows the breakthrough curve, on natural chitosan, in the central point a flow rate of $4.1 \mathrm{~mL} / \mathrm{min}$ and an initial concentration of $150 \mathrm{mg} . \mathrm{L}^{-1}$.

From the Figure 1 it is possible to observe that the breakthrough occurred almost immediately in the beginning of the processes, due to the low kinetic rate of chromium ions on chitosan membranes ${ }^{11}$. This phenomenon is mainly influenced by chitosan and chromium ion affinity and the membrane geometry used, since its size was large compared to the column dimensions. The intention of this work was indeed to analyze the affinity between adsorbent and adsorbate in a dynamic process, whereas the static process was previously studied, giving satisfactory results ${ }^{11}$. The conditions of experiments were chosen according to the average requirements found in such adsorptive systems: the concentration of solution to be treated was set by the amount of pollutants; the amount of chitosan placed within the column was mostly limited by chitosan density and, hence, by the volume to fill an adsorption column; and the flow rate was limited by the volume of effluent to be treated.

From a practical point-of-view, if the breakthough occurs very quickly, the best configuration to use this technology will probably be the application of many columns in a parallel feature.

Comparing the breakthrough curves of Figure 1 (a) with that of 1 (c), where the concentrations were $50 \mathrm{mg} . \mathrm{L}^{-1}$, it is possible to observe that, while the flow rate increased from 2.7 to $5.5 \mathrm{~mL} / \mathrm{min}$, the values of $\mathrm{C}(\mathrm{t}) / \mathrm{C}_{\mathrm{i}}$ did not change significantly for each kind of adsorbent. Similar observations can be gathered when comparing the plots of Figures 1 (b) and 1 (d), where the concentrations were $250 \mathrm{mg} . \mathrm{L}^{-1}$. It indicates that the variation in flow rate did not present a high influence in the adsorption process, showing that the external diffusion is the most rate limiting.

Comparing the breakthrough curves from Figures 1 (a) and 1 (b), where the flow rate was kept constant and equal to $2.7 \mathrm{~mL} / \mathrm{min}$ and the solution concentration was increased from 50 to $250 \mathrm{mg} . \mathrm{L}^{-1}$, a change in the curve's shape can be observed. Then, by increasing the solution concentration from 50 to $250 \mathrm{mg} . \mathrm{L}^{-1}$, the adsorption kinetics changed, once the equilibrium was reached faster in the latter case. The same result is observed when comparing the breakthrough curves from Figures 1 (c) with 1 (d), where the flow rates were $5.5 \mathrm{~mL} / \mathrm{min}$. The curves from the triplicates suggest a reproducibility that can be considered satisfactory. The adsorbed amount of chromium ions in each experimental run is showed in Table 3. Chromium ions adsorption on chitosan has slow kinetic rates and in some experiments the equilibrium was not reached. This fact explains the difference in the adsorbed amount at different flow rate, for example to natural chitosan at initial concentration of $250 \mathrm{mg} \cdot \mathrm{L}^{-1}$.

The highest values of adsorbed metal quantity were those found for chitosan crosslinked with glutaraldehyde (nearly twice the value found for other membranes). Even with the crosslinking process induced with glutaraldehyde, an increase in adsorption capacity occurred. Similar results were obtained by Vieira and Beppu ${ }^{15,19,20}$, who studied mercury adsorption on chitosan using static and dynamic methods. Machado et al. ${ }^{21}$ shows an increase in copper adsorption after glutaradehyde crosslinking reaction, and this fact is attributed to the amount of free amino groups, as there would be less protonated amino groups in the crosslinked matrices. The same effect could be causing the observed results for chromium ions.

According to Hsien and Rorrer ${ }^{14}$ an increase in adsorbing cations after crosslinking process is explained by the increase in space among chitosan chains, which is responsible for an improvement in the accessibility of the metallic ions to amino groups. In this way, an enhancement in the adsorption capacity can be interpreted as a result of increasing the accessibility for metallic ions due to the partial destruction of the crystalline structure ${ }^{22}$. According to Kurita et al. $^{23}$ the crystallinity has a fundamental role in the accessibility of adsorbent groups to metallic ions and many studies have been trying to demonstrate that when crystallinity is reduced, an increase in adsorptive capacity is promoted. Beppu and Santana ${ }^{12}$ showed through X-ray diffraction that a decrease in crystallinity occurs on membranes crosslinked with glutaraldehyde compared to the

Table 3. Adsorbed amount of chromium ions in each experimental run.

\begin{tabular}{|c|c|c|c|c|}
\hline & $\begin{array}{l}\text { Flow rate } \\
(\mathrm{mL} / \mathrm{min})\end{array}$ & $\begin{array}{l}\text { Initial concentration } \\
\left(\mathrm{mg} . \mathrm{L}^{-1}\right)\end{array}$ & $\begin{array}{l}\text { Adsorbed amount } Q_{\text {wet }} \\
\left(\mathrm{mg} \cdot \mathrm{g}^{-1} \text { wet chitosan) }\right.\end{array}$ & $\begin{array}{l}\text { Adsorbed amount } Q_{\text {dry }} \\
\left(\mathrm{mg} \cdot \mathrm{g}^{-1} \text { dry chitosan }\right)\end{array}$ \\
\hline \multirow[t]{4}{*}{ Natural Chitosan } & 2.70 & 50 & 0.54 & 8.9 \\
\hline & & 250 & 3.05 & 50.0 \\
\hline & 5.50 & 50 & 0.43 & 7.0 \\
\hline & & 250 & 1.77 & 29.1 \\
\hline \multirow[t]{4}{*}{ GLA-Chitosan } & 2.70 & 50 & 0.82 & 9.7 \\
\hline & & 250 & 4.11 & 48.3 \\
\hline & 5.50 & 50 & 1.32 & 15.5 \\
\hline & & 250 & 2.83 & 33.4 \\
\hline \multirow[t]{4}{*}{ ECH-Chitosan } & 2.70 & 50 & 0.91 & 13.2 \\
\hline & & 250 & 1.97 & 28.5 \\
\hline & 5.50 & 50 & 0.68 & 9.9 \\
\hline & & 250 & 1.81 & 26.3 \\
\hline \multirow{3}{*}{$\begin{array}{l}\text { Triplicate - Natural } \\
\text { Chitosan }\end{array}$} & 4.10 & 150 & 0.49 & 8.1 \\
\hline & & & 1.02 & 16.7 \\
\hline & & & 1.27 & 20.9 \\
\hline
\end{tabular}


natural one. Monteiro and Airoldi ${ }^{24}$ studied the adsorption capacity of chitosan for $\mathrm{Cu}$ (II) ions and it was observed that copper remains adsorbed onto chitosan even after crosslinking with glutaraldehyde. The authors supposed that the new structure formed by crosslinking reaction, imino bounds, is able to adsorb copper ions.

The adsorption results obtained for natural and epichlorhydrincrosslinked chitosan were quite similar, which indicates the possibility of the adsorption of metallic ions can take place on amino groups, which are available, and in less proportion on hydroxyl groups, which can be unavailable by crosslinking reaction. These results are in accordance with Baroni et al. ${ }^{11}$ and Vieira and Beppu ${ }^{15}$ who investigated the adsorption mechanism of chromium and mercury ions on chitosan using FTIR-ATR. The authors demonstrated that the metal interaction is mainly due to the characteristic of the chitosan, such as, if the material is crosslinked or not and the kind of croslinking agent.

The glutaraldehyde-crosslinked chitosan provides the best quantitative results for chromium adsorption, but the natural chitosan offers advantage of not needing further chemical transformation and can be suitable for application in real situations.

The evaluation of chromium desorption from chitosan is very important to verify the possibility of its reuse. Some desorption experiments were performed in static processes, such as previously described by Baroni et al. ${ }^{11}$ and desorption of $48.6 \%$ for chromium total ions at $\mathrm{pH}=6.0$ was observed on natural chitosan. In addition, chitosan membranes were submitted for three cycles of adsorption/desorption, indicating a favorable possibility of chitosan reutilization ${ }^{11}$.

By using Minitab ${ }^{\circledR}$ software, Pareto diagrams were obtained for factors studied in the experimental plan (Figures 2a, b and c) for natural chitosan. Any value that goes beyond the red line in the diagram has a significance level of 0.05 , representing a confidence of $95 \%$. The p-value can also be seen in the same figures.

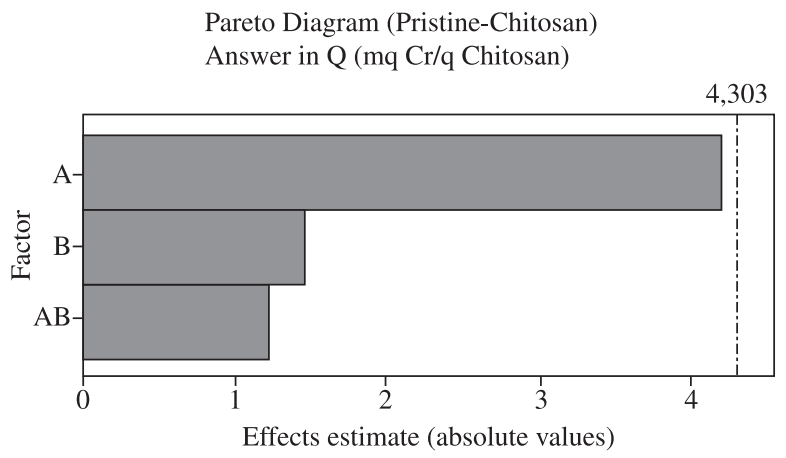

(a)
Table 4 depicts the statistical data related to adjustment of results with $\mathrm{R}^{2}$ adjusted parameters. Table 4 depicts the effects that each factor causes in the system, i.e. the resultant quantitative effect due to a modification of a factor. Table 4 and the Pareto diagram in Figure 2 (a) indicate that the most important effect in the amount of metal adsorbed was the initial solution concentration (A), followed by flow rate (B) and the interaction between these two effects (AB). The positive value of 1.667 of the concentration effect $\left(\mathrm{C}_{\mathrm{i}}\right)$ indicates that an increase in the concentration causes an increase in the chromium adsorption. Similarly, a negative value in some factors indicates that when increasing the value of this factor the effect is decreased. The concentration factor presented trustable p-values (0.052), while flow rate and the interaction between these two effects showed high p-values.

Analyzing the plot from Figure 2 (A), it was possible to say that the concentration effect has the biggest absolute values being the main effect on the analyzed response.

The coefficient values of Table 4 give the Equation 4 which represents the quantity of adsorbed metal as a function of the flow rate and the initial concentration from chromium solution, using natural chitosan.

$$
\begin{aligned}
& \mathrm{Q}=1.3078+0.8338 . C i-0.2888 . W-0.2438 . \\
& \text { Ci } . W-0.3819 .(P t . C(t))
\end{aligned}
$$

where $P . C(t)$ is the central point mean.

$\mathrm{R}^{2}$ (adjusted) of $75.87 \%$ shows that the linear model of the factorial explains poorly the behavior of chromium ion adsorption on chitosan biopolymer. One reason for that can be the attributed to a possible non-linearity of the response - factor relationship.

The Pareto diagrams from Figures 2 (b) and 2 (c) also indicate that the initial concentration of chromium solution presents the main effect among the studied factors. This concentration is usually a fixed

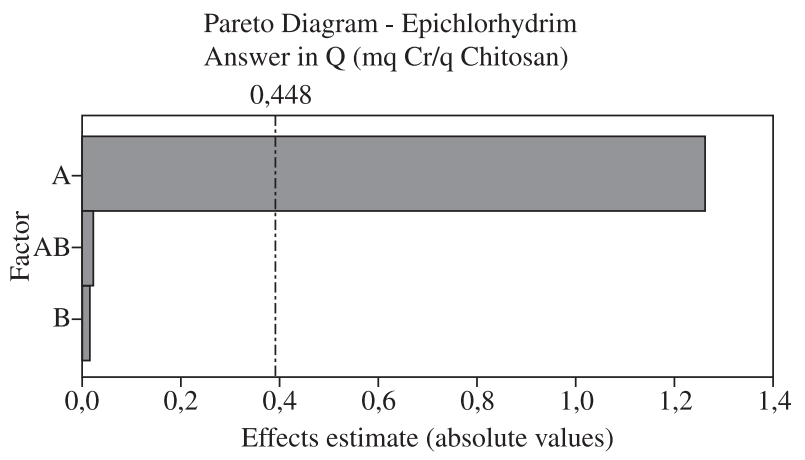

(b)

Pareto Diagram - Glutaraldehyde

Answer in Q (mq Cr/q Chitosan)

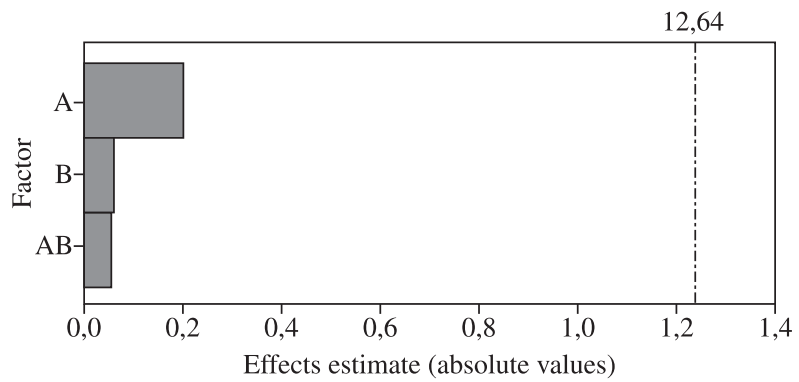

(c)

Figure 2. (a), (b) and (c) - Pareto diagrams for natural, epichlorohydrin-crosslinked and glutaraldehyde-crosslinked chitosan membranes, respectively. A = concentration, $\mathrm{B}=$ flow rate, $\mathrm{AB}=$ interaction between $\mathrm{A}$ and $\mathrm{B}$. 
Table 4. Statistical adjustment data for natural chitosan.

\begin{tabular}{lccc}
\hline \multicolumn{1}{c}{ Factor } & Effect & Coefficient & $\mathrm{p}$ \\
\hline Constant & $*$ & 1.3078 & 0.022 \\
$\mathrm{C}_{\mathrm{i}}\left(\mathrm{mg} . \mathrm{L}^{-1}\right)$ & 1.6675 & 0.8338 & 0.052 \\
Flow rate $(\mathrm{mL} / \mathrm{min})$ & -0.5775 & -0.2888 & 0.283 \\
$\mathrm{C}_{\mathrm{i}}\left(\mathrm{mg} . \mathrm{L}^{-1}\right) *$ Flow rate $(\mathrm{mL} / \mathrm{min})$ & -0.4875 & -0.2438 & 0.344 \\
$\mathrm{Pt} * \mathrm{C}(\mathrm{t})$ & $*$ & -0.3819 & 0.335 \\
\hline $\mathrm{R}^{2}$ (adjusted $)=75.87 \%$ & & &
\end{tabular}

condition of the industrial effluent to be treated and usually cannot be changed, mainly if the required condition is a more concentrated solution. Hence, one could say that the use of chitosan as adsorbent is limited to a non-controllable factor such as the initial concentration of chromium; however, many cycles of adsorption could be applied to result in a given required purification.

Further analyses are being performed in the group in order to propose a model of chromium ion adsorption and to elucidate the species that are at last being adsorbed onto chitosan surface.

\section{Conclusions}

Dynamic adsorption in fixed bed experiments presented satisfactory results regarding to the adsorption capacity of chromium. The slow kinetic rate of chromium ions resulted in a breakthough very quickly; however it was possible to analyze the effect of flow rate, initial concentration and crosslinking reaction on adsorbed amount.

Initial chromium solution concentration is the main factor from the ones that were considered, as it influences chitosan adsorption capacity, establishing a positive relationship between these variables.

The crosslinking performed on chitosan with glutaraldehyde was the condition, among other chemical treatments, that presented the highest chromium uptaking capacity. Although being satisfactory, the other two forms of chitosan presented similar adsorption capacity, lower than the capacity exhibited by glutaraldehyde-crosslinked chitosan.

\section{Acknowledgements}

The authors thank FAPESP and CNPq for their financial support and scholarship.

\section{References}

1. Rapsomanikis S, Craig PJ. Speciation of Mercury and Methylmercury Compounds in Aqueous Samples by Chromatography-Atomic Absorption Spectrometry after Ethylation with Sodium Tetraethylborate. Analytica Chimica Acta. 1991; 248(2):563-567.

2. Nieboer E, Jusys AA. Biologic chemistry of chromium. In: Nriagu, JO and Nieboer E, editor. Chromium in Natural and Human Environments. New York: Wiley Interscience; 1988.

3. Kotas J, Stasicka S. Chromium Occurrence in the environment and methods of its speciation. Environmental Pollution. 2000; 107(3):263-283.

4. Duta FP, Franca FP, Costa ACA. The performance of a continuous system for biosorption and desorption of zinc, cadmium, manganese and copper by the seaweed Sargassum sp. European Journal of Mineral Processing Environmental Protection. 2002; 2(3):131-140.

5. Bailey SE, Olin TJ, Bricka RM, Adrian DD. A review of potentially low-cost sorbents for heavy metals. Water Research. 1999; 33(11):2469-2479.
6. Crini G, Badot PM. Application of chitosan, a natural aminopolysaccharide, for dyeremoval from aqueous solutions by adsorption processes usingbatch studies: A review of recent literature. Progress in Polymer Science. 2008; 33(4):399-447.

7. Trimukhe KD, Varma AJ. Complexation of heavy metals by crosslinked chitin and its deacetylated derivatives. Carbohydrate Polymers. 2008; 71(1):66-73.

8. Gerente C, Lee VKC, Cloirec PL, McKAY G. Application of Chitosan for the Removal of Metals From Wastewaters by Adsorption-Mechanisms and Models Review. Critical Reviews in Environmental Science and Technology. 2007; 37(1):41-127.

9. Bassi R, Prasher SO, Simpson BK. Removal of selected metal ions from aqueous solutions using chitosan flakes. Separation Science Technology. 2000; 35(4):547-560.

10. Guibal E. Interactions of metal ions with chitosan-based sorbents: A Review. Separation Purification Technology. 2004; 38(1):43-74.

11. Baroni P, Vieira RS, Meneghetti E, da Silva MGC, Beppu MM. Evaluation of batch adsorption of chromium ions on natural and crosslinked chitosan membranes. Journal of Hazardous Materials. 2008; 152(3):1155-1163.

12. Beppu MM, Santana CC. PAA influence on chitosan membrane calcification. Materials Science Engineering C. 2003; 23(5):651-658.

13. Wei YC, Hudson SM, Mayer JM, Kaplan DL. The crosslinking of chitosan fibers. Journal of Polymer Science Part A: Polymer Chemistry. 1992; 30(10):2187-2193.

14. Hsien TY, Rorrer GL. Effects of Acetylation and Crosslinking on The Material Properties and Cadmium Ion Adsorption Capacity of Porous Chitosan Beads. Separation Science Technology. 1995; 30(12):2455-75.

15. Vieira RS, Beppu MM. Interaction of natural and crosslinked chitosan membranes with $\mathrm{Hg}(\mathrm{II})$ ions. Colloids Surface A - Physicochemical and Engineering Aspects. 2006; 79(1-3):196-207.

16. Box GEP, Hunter WG, Hunter JS. Statistics for experimenters: an introduction to design, data analysis, and model building. New York: J. Wiley; 1978.

17. Dambies L, Guimon C, Yiacoumi S, Guibal E. Characterization of metal ion interactions with chitosan by X-ray photoelectron spectroscopy. Colloids Surface A - Physicochemical and Engineering Aspects. 2001; 177(2-3):203-214.

18. Boddu VM, Abburi K, Talbott JL, Smith ED. Removal of hexavalent chromium from wastewater using a new composite chitosan biosorbent. Environmental Science Technology. 2003; 37(19):4449-4456.

19. Vieira RS, Beppu MM. Mercury ion recovery using natural and crosslinked chitosan membranes. Adsorption, 2005; 11(1):731-736.

20. Vieira RS, Beppu MM. Dynamic and static adsorption and desorption of $\mathrm{Hg}$ (II) ions on chitosan membranes and spheres. Water Research. 2006; 40(8):1726-1734.

21. Machado MO, Lopes ECN, Sousa KS, Airoldi C. The effectiveness of the protected amino group on crosslinked chitosans for copper removal and the thermodynamics of interaction at the solid/liquid interface. Carbohydrate Polymers. 2009; 77(4):760-766.

22. Koyama Y, Taniguchi A, Huang CP, Blakenship DW. Studies on chitin. X. Homogeneous cross-linking of chitosan for enhanced cupric ion adsorption. Journal of Applied Polymer Science. 1986; 31(6):1951-1954.

23. Kurita K, Sannan T, Iwakura, Y. Studies on Chitin. VI. Binding of Metal Cations. Journal of Applied Polymer Science. 1979; 23(2):511-515.

24. Monteiro Jr. OAC, Airoldi C. Some studies of crosslinking-glutaraldehyde interaction in a homogeneous system. International Journal of Biological Macromolecules. 1999; 26(2-3):119-128. 